DENNY MILITELLO

\title{
A PARTILHA DE QUOTAS SOCIAIS NA DISSOLUÇÃO DO VÍNCULO MARITAL E O USO ILÍCITO DA PESSOA JURÍDICA PARA FRAUDAR A MEAÇÃO
}

\author{
Dissertação de Mestrado \\ Orientador: Professor Titular Dr. Carlos Alberto Dabus Maluf
}

UNIVERSIDADE DE SÃO PAULO

FACULDADE DE DIREITO

São Paulo-SP

2017 


\title{
A PARTILHA DE QUOTAS SOCIAIS NA DISSOLUÇÃO DO VÍNCULO MARITAL E O USO ILÍCITO DA PESSOA JURÍDICA PARA FRAUDAR A MEAÇÃO
}

\begin{abstract}
Dissertação apresentada à Banca Examinadora do Programa de Pós-Graduação em Direito, da Faculdade de Direito da Universidade de São Paulo, como exigência parcial para obtenção do título de Mestre em Direito, na área de concentração Direito Civil, sob a orientação do Professor Titular Dr. Carlos Alberto Dabus Maluf.
\end{abstract}

UNIVERSIDADE DE SÃO PAULO

FACULDADE DE DIREITO

São Paulo-SP

2017 


\section{Catalogação da Publicação}

Militello, Denny

A partilha de quotas sociais na dissolução do vínculo marital e o uso ilícito da pessoa jurídica para fraudar a meação / Denny Militello. -- São Paulo: USP / Faculdade de Direito, 2017.

148f.

Orientador: Professor Titular Dr. Carlos Alberto Dabus Maluf

Dissertação (Mestrado), Universidade de São Paulo, USP, Programa de PósGraduação em Direito, Direito Civil, 2017.

1. Direito de família. 2. Casamento. 3. União estável. 4. Dissolução. 5. Partilha. 6. Cotas sociais. I. Maluf, Carlos Alberto Dabus. II. Título. 
BANCA EXAMINADORA

Professor:

Instituição:

Professor:

Instituição:

Professor:

Instituição: 
A meu pai, in memoriam.

Ele, que sempre foi meu maior exemplo de dedicação à família e ao trabalho e principal entusiasta de meu crescimento profissional. 


\section{AGRADECIMENTOS}

Agradeço, primeiramente, a meu orientador, Professor Dr. Carlos Alberto Dabus Maluf, pela oportunidade e, acima de tudo, pela confiança depositada em mim, quando há 3 (três) anos submeti ao processo seletivo e fui aceito por ele na terceira e última fase do para ingresso no curso de mestrado na Faculdade de Direito da Universidade de São Paulo.

Também agradeço a convivência ao longo do curso e o aprendizado, além das lições obtidas em meio às aulas da pós-graduação, mas as advindas da prática da docência, no seu dia-a-dia, quando participei do Estágio Supervisionado em Docência.

Além da academia, a vida me presentou com muitos professores. Perante a advocacia, sou muito grato a todos os que tive no exercício diário da profissão. Devo muito de minha formação profissional ao caríssimo amigo João Carlos Duarte de Toledo. O dia-adia profissional de 2008 a 2010 e, posteriormente, de 2012 a 2016 contribuíram muito para meu desenvolvimento como advogado e, acima de tudo, como pessoa. São valiosíssimas as lições que recebi para o desenvolvimento de minha carreira, mas, sobretudo, no amadurecimento como ser humano.

Em nome do João Carlos Duarte de Toledo, ainda, estendo meus agradecimentos a todos os demais profissionais que dividiram comigo o dia-a-dia - e as madrugadas também - no Madrona Advogados. Ao Ricardo Madrona, obrigado pelo exemplo de profissional que sempre foi para o desenvolvimento de minha carreira.

Em especial, ainda, agradeço ao Professor Oscarlino Moeller, Desembargador aposentado e advogado consultor, a quem fui privilegiado de poder discutir, ainda antes do meu ingresso no curso de pós-graduação stricto sensu, acerca de potenciais temas a serem desenvolvidos em dissertação de mestrado. Meu agradecimento, ainda, supera o privilégio do debate de questões afeitas ao Direito, mas também ao constante incentivo que recebi ainda quando dividia a rotina à época em que advogado associado do Madrona Advogados.

Agradeço ao Marcelo Roitman pelas importantes lições na advocacia, enquanto exerci o cargo de advogado no Pompeu, Longo, Kignel \& Cipullo Advogados. Também agradeço a Adriano Fontes Pinto e Rafael Gomes de Almeida, que, além de colegas de trabalho e responsáveis também pelo meu crescimento profissional em nossos intensos e 
quase que diários debates envolvendo a advocacia e o Direito, tornaram-se verdadeiros amigos para uma vida.

Não menos importante, agradeço, ainda, aos amigos do Demarest Advogados. A amizade, convivência diária e compartilhamento de objetivos me inspiram a buscar cada dia mais um maior crescimento, de modo a alçar voos cada vez mais altos na advocacia. Sou muito grato por poder compartilhar atualmente minha vida profissional com vocês e enxergo um futuro incrível. A lista de pessoas que gostaria de incluir aqui é tão extensa que o bom senso recomenda a não citação nominal, até para evitar o risco de cometer alguma injustiça e deixar de citar alguém. A todos, meu muito obrigado.

Estendo, ainda, o agradecimento a toda equipe de suporte da biblioteca do escritório, que muito paciente e diligentemente separaram livros e mais livros nos últimos meses antes do depósito da dissertação para o desenvolvimento de minha pesquisa. Não concluiria minha dissertação de mestrado se não fosse a ajuda destes profissionais e do acervo bibliográfico do Demarest Advogados.

À minha família, agradeço simplesmente por tudo. Minha formação como ser humano, os constantes incentivos, apoio e exemplo. Também agradeço por sempre terem estado do meu lado, antes, durante e depois de todas as minhas escolhas feitas na vida. Especialmente, a minha mãe, Luciana Militello, meu carinho e exemplo de pessoa.

Agradeço, ainda, profundamente a Priscilla Soares de Oliveira, com quem dividi todos os momentos de desenvolvimento deste trabalho. Sua paciência, suas valiosas contribuições em meio as nossas conversas do dia-a-dia e madrugadas a dentro, além de seu apoio, são plenamente merecedoras de minha profunda gratidão. Se já não fosse suficiente, contei com sua importantíssima ajuda e pertinentíssimas críticas para finalização do trabalho, em meio às intermináveis revisões de conteúdo. Obrigado por tudo! 
MILITELLO, Denny. A partilha de quotas sociais na dissolução do vínculo marital e o uso ilícito da pessoa jurídica para fraudar a meação. 2017. 148f. Dissertação (Mestrado) Faculdade de Direito, Universidade de São Paulo, São Paulo, 2017.

\section{RESUMO}

Essa dissertação de mestrado relata as formas de extinção do vínculo afetivo entre o casal. Trata da partilha de bens na dissolução do vínculo e os vícios que lhe podem acometer, tanto do ponto de vista consensual quanto litigioso. Especifica as formas de remediar eventual prejuízo sofrido em virtude de vícios e fraudes à meação. Aborda o conceito de quota social, capital social e patrimônio social. Comenta as formas de determinação e liquidação das quotas sociais. Analisa a ação de dissolução parcial de sociedade e formas de apuração de haveres. Finalmente, elenca algumas formas usuais de se fraudar a meação, principalmente, com o uso das prerrogativas da pessoa jurídica e analisa a teoria da desconsideração inversa da personalidade jurídica aplicada no direito de família.

Palavras-Chave: Casamento. União Estável. Dissolução. Partilha. Quotas Sociais. Apuração de Haveres. Dissolução parcial de sociedade. Fraude à meação. Desconsideração inversa da personalidade jurídica no direito de família. 
MILITELLO, Denny. The division of corporate shares belonging to the community property as per the termination of the affective relationship and the fraudulent use of the corporate veil to hide marital assets in the equitable division. 2017. 148p. Dissertation for Master's Degree - Faculty of Law, University of São Paulo, São Paulo, 2017.

\begin{abstract}
This study reports the forms of termination of the marriage and consensual marriage between the couple. Treats about the equitable division of community property, whether consensual or non-consensual, referring to possible consensual vices or other frauds that can affect it. Specifies the remedies set forth in the law to avoid to suffer losses and damages or recover them in case of occurrence of such vices or frauds. Refers to the definition of the concept of corporate shares, legal capital and its relation to the corporates' properties. Comments differents forms to evaluate the corporate shares and the procedure involving the dissolution of the enterprise or closed corporation lawsuit. Finally, lists usual acts practiced to hide marital assets or anyway fraud the equitable division related to the community property, mainly, with simulated transactions involving companies and corporations and analysis the disregard of corporate entity or piercing the corporate veil doctrines, in its reverse form ("reverse piercing") as a remedy against such acts of fraud before the family law.
\end{abstract}

Keywords: Marriage. Consensual Marriage. Termination of the relationship. Equitable division of community property. Corporate Shares. Evaluation of Corporate Shares. Dissolution of Companies or Closed Corporations. Fraud committed to hide marital assets. Disregard of Corporate Entity or Piercing of the Corporate Veil in its reverse form (piercing reverse) in Family Law. 


\section{SUMÁRIO}

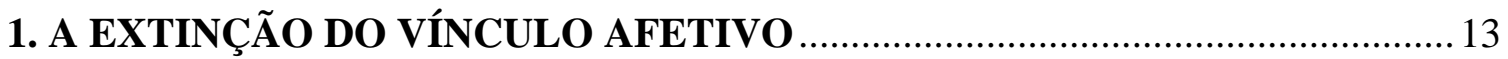

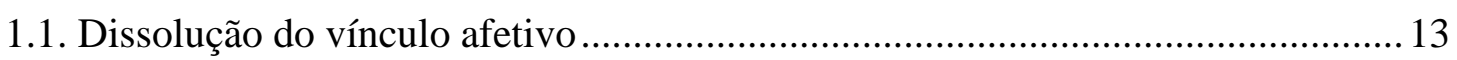

1.1.1. Dissolução da união conjugal.................................................................. 13

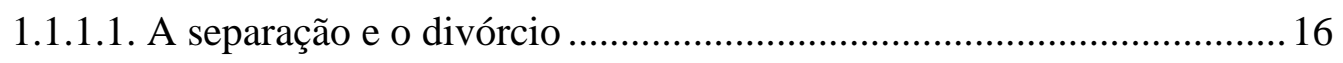

1.1.1.2. A Emenda Constitucional no $66 / 2010$.................................................. 22

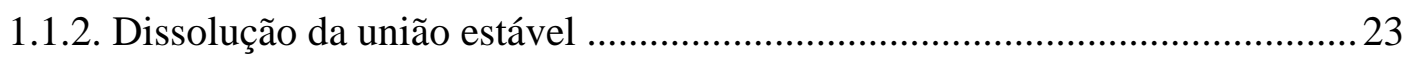

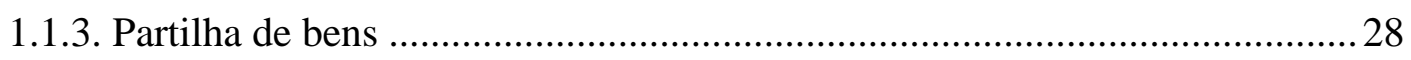

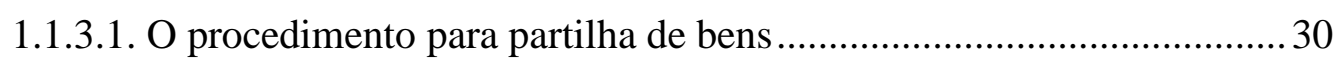

1.1.3.2. A partilha perante o Poder Judiciário .................................................... 32

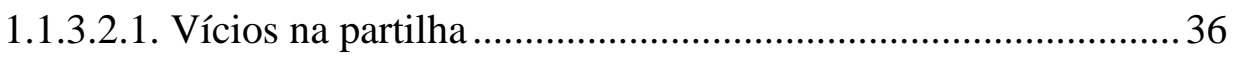

1.1.3.2.1.1. Os vícios de consentimento na partilha consensual: prejuízo ao meeiro ................................................................ 38

1.1.3.2.1.2. Fraude contra credores como vício de consentimento na partilha consensual: prejuízo ao(s)

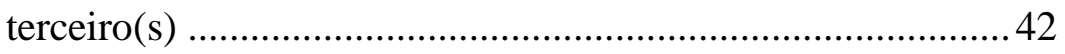

1.1.3.2.1.3. A rescisão da sentença na partilha litigiosa ............. 45

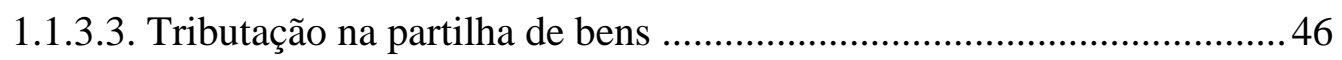

1.1.3.3.1. A incidência do Imposto de Transmissão Causa Mortis ITCMD ou Imposto de Transmissão de Bens Imóveis - ITBI

1.1.3.3.2. A incidência do Imposto de Renda .......................................... 49

\section{A PARTILHA de QUOTAS SOCIAIS NA DisSOluÇÃo do VÍNCULO}

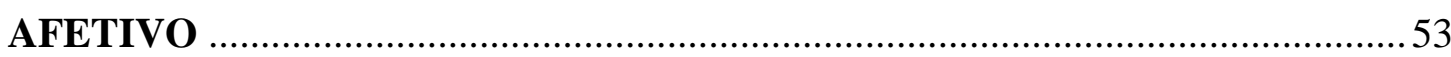

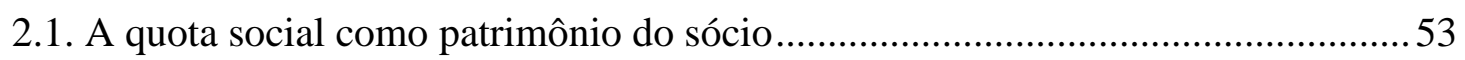

2.1.1. Capital social x patrimônio social .................................................................59

2.1.2. A determinação e liquidação da(s) quota(s) social(is) ................................. 67

2.1.2.1. A liquidação da quota social em prol do meeiro do sócio, para o caso de extinção do vínculo afetivo

2.1.2.2. A liquidação da quota social ao ex-cônjuge ou ex-companheiro uma vez parte ilegítima para ajuizar ação de dissolução parcial .................... 84

2.1.2.2.1. O recebimento dos haveres por meio de ação de separação, divórcio ou dissolução da união estável 
2.1.2.2.2. A anuência ao ingresso do meeiro no capital social da sociedade ou a necessidade de se aguardar a liquidação da sociedade, concorrendo aos lucros

2.1.2.3. O recebimento dos haveres por meio de ação de dissolução parcial e o artigo 600, parágrafo único, do Código de Processo Civil de 2015 ....89

2.1.3. A partilha da valorização da quota social detida pelo sócio antes do vínculo afetivo, em caso de regime de comunhão parcial ou participação final nos aquestos 94

2.1.4. Tributação na dissolução parcial da sociedade. .99

3. A FRAUdE À MEAÇÃO PELO USO ILÍCITO DA PESSOA JURÍDICA 103

3.1. Breves linhas sobre fraude 104

3.2. A fraude do ponto de vista do direito de família especificamente para prejudicar a meação 106

3.3. O uso da pessoa jurídica para fraudar a meação 109

3.4. A desconsideração inversa da personalidade jurídica aplicada ao Direito de Família 114

3.4.1. Breves apontamentos sobre a desconsideração da personalidade jurídica .... 114

3.4.2. A desconsideração inversa da personalidade jurídica 121

3.4.2.1. A desconsideração inversa como forma de reprimir a fraude à meação

3.4.3. O procedimento para a desconsideração da personalidade jurídica, segundo o Código de Processo Civil de 2015 128 


\section{INTRODUÇÃO}

O presente trabalho busca analisar a ruptura da relação afetiva e suas consequências patrimoniais, debruçando-se sobre a partilha, especialmente quando há divisão de quotas sociais, bem como sobre o uso ilícito da pessoa jurídica para fraudar a meação.

Inicialmente, serão analisadas as formas de ruptura da relação afetiva. De um lado, abordar-se-á a separação e o divórcio, efetuando-se um escorço histórico a respeito, contemplando, inclusive, a indissolubilidade do casamento. Tratar-se-á da separação como alternativa à indissolubilidade do casamento, como forma de dissolver a sociedade sem extinguir o vínculo. E, ao fim, o divórcio.

A evolução do regime legal brasileiro antidivorcista para um regime divorcista, especialmente após Emenda Constitucional nº 66/2010 também será tratado, ainda que lateralmente, no presente trabalho.

De outro lado, referir-se-á também à dissolução da união estável. Nesse trabalho, evitou-se aprofundar muito questões tais como a evolução do instituto e seu reconhecimento como entidade familiar, salvo as implicações do ponto de vista patrimonial, quando do final da relação de convivência.

Nesse sentido, restará claro que o reconhecimento ao direito da partilha no término da união estável adveio, primeiramente, por força de construção jurisprudencial. A Súmula n 380 do Supremo Tribunal Federal, editada no ano de 1964, confirma tal hipótese. Os conviventes ainda não eram vistos como parte de uma entidade familiar. A ação de dissolução de sociedade de fato tramitava perante as Varas Cíveis e não Vara de Família. Diferentemente do casamento, a partilha dos bens era feita segundo a contribuição de cada casal ao patrimônio erigido, vindo a ser apenas posteriormente positivada a partilha igualitária.

Esclarecidas as nuances da ruptura do vínculo afetivo, passar-se-á ao item seguinte: a partilha dos bens, especialmente quando parte dos bens comuns são quotas sociais. Visouse, primeiro, a explicar a partilha para, apenas então, no Capítulo 2 , referir-se à divisão das quotas sociais entre os consortes, quando estas compuserem os bens comuns.

Nesse sentido, será abordado o procedimento para a partilha, judicial ou extrajudicial, bem assim os vícios que a podem acometer, quer seja quando consensual - via vícios de 
consentimento - quer seja litigiosa. Ao referir aos vícios de consentimento, busca-se esclarecer que tais vícios na partilha podem ocorrer tanto para prejudicar o meeiro, quanto para prejudicar terceiros, quando em caso de fraude contra credores.

Ao fim do Capítulo 1, será estudado o regime de tributação da partilha: a eventual incidência na partilha do Imposto sobre Transmissão Causa Mortis e Doação - ITCMD ou do Imposto sobre Transmissão de Bens Imóveis - ITBI, e o regime de tributação de ganhos de capital, em se tratando de Imposto de Renda Pessoa Física - IRPF são algumas questões que se pretendeu abordar e esclarecer.

No Capítulo 2, a quota social será objeto central: a definição de seu conceito, sua relação com o capital social e com o patrimônio social. Explicitado isso, aprofundar-se-á sobre a denominada determinação da quota social, isto é, a apuração de quanto representa a participação societária do sócio, no caso, cônjuge ou companheiro, na sociedade, para fins de pagamento de seus haveres ao meeiro.

Essa abordagem demonstra-se importante para o trabalho, pois, como será exposto ainda no Capítulo 2, o meeiro apenas passa a ser sócio dos sócios do consorte no caso de anuência destes (ou não oposição no caso das sociedades limitadas), sustentando, do contrário, uma posição de sub-sócio com o seu ex-consorte.

Como será demonstrado, isso significa dizer que o sub-sócio não exerce nenhum direito político diretamente na sociedade, detendo direito tão somente ao recebimento da distribuição regular de dividendos até a liquidação da sociedade. Nesse quadrante, tratar-seá da evolução jurisprudencial, agora positivada no Código de Processo Civil de 2015, acerca da legitimidade de ajuizamento, pelo cônjuge ou companheiro, de ação de dissolução parcial de sociedade, visando ao recebimento dos haveres que lhe são devidos.

Sobre esse aspecto, pretende-se demonstrar que, decerto, a opção construída na jurisprudência e ora erigida a dispositivo legal de forma a possibilitar a dissolução parcial da sociedade requerida pelo ex-consorte, evita situação desgastante de manutenção de seu vínculo com a sociedade.

Também será objeto de estudo o contraponto defendido pelos opositores a essa prerrogativa do meeiro, qual seja a oneração excessiva do patrimônio social da sociedade, que deverá pagar-lhe os haveres como se fosse a um sócio, ainda que pelo valor relativo à meação, muitas vezes sem respaldo em um fluxo de caixa suficiente para tal pagamento. Nesse ponto, abordar-se-á a necessidade de que as formas de apuração de haveres e 
pagamento estejam bem delineadas no contrato social da sociedade, a fim de se evitar situações passíveis de inviabilizar e/ou comprometer a continuidade da empresa.

Ainda com relação à ação de dissolução parcial, analisar-se-á o novo regime processual, segundo o Código de Processo Civil de 2015, ainda que sem muitos elementos doutrinários e jurisprudenciais, dada sua recém promulgação. Ao fim, abordar-se-á o tratamento fiscal ao pagamento dos haveres. Tais questões e ainda outras serão abordadas no Capítulo 2.

Finalmente, no Capítulo 3, serão tratadas especificamente algumas das possíveis formas de se fraudar a meação, especialmente mediante o uso da pessoa jurídica. Ressalvase, porém, desde já, que esgotar tal matéria, descrevendo-se, uma a uma, todas as formas possíveis de fraude, é tarefa impossível. Como veremos, o ser humano é dotado de tamanha criatividade e astúcia, que é capaz de elaborar, continuamente, novos estratagemas como forma de fraudar o direito do meeiro.

Sob esse cenário, demonstrar-se-á, também, que as operações fraudulentas, normalmente, contam com o apoio de pessoas interpostas, denominadas popularmente como "laranjas", as quais viabilizam a execução de tais fraudes.

Ao cabo do Capítulo 3, será objeto de análise a teoria da desconsideração da personalidade jurídica, na sua forma inversa, como instrumento hábil a remediar tais atos fraudulentos, que via de regra se apoiam na distinção e autonomia do patrimônio da sociedade de seus sócios, como forma de burlar a meação.

Para tanto, iniciou-se uma abordagem acerca do instituto, originariamente, relativamente à desconsideração da personalidade jurídica, mencionando julgados em outros locais do mundo além do Brasil, para então, posteriormente, abordar a sua forma inversa.

Também se referir-se-á ao incidente previsto no Código de Processo Civil de 2015 acerca da efetivação da desconsideração da personalidade jurídica, considerando-se que, pela primeira vez no ordenamento jurídico brasileiro, previu-se em lei o procedimento do ponto de vista formal para aplicação da teoria da desconsideração da personalidade jurídica.

Assim, convida-se o leitor a explorar os assuntos em testilha nas páginas seguintes. 


\section{CONCLUSÃO}

À guisa de conclusão, em meio ao desenvolvimento do presente trabalho, demonstrou-se que a separação, divórcio e dissolução de união estável vem ocorrendo de maneira crescente, comprovado, inclusive, estatisticamente (cf. Capítulo 1), de modo que o estudo e desenvolvimento de temas acerca de suas características, nuances e implicações patrimoniais demonstra-se, a cada dia, mais importante.

Dentro desse cenário, inclui-se a temática central desse trabalho: a partilha das quotas sociais quando da dissolução do vínculo afetivo e o uso da pessoa jurídica para fraudar a meação.

A despeito da especificidade do tema, a casuística demonstra que tanto a partilha das quotas sociais quanto a fraude à meação são bastante comuns na vivência forense.

O tema abordado, ainda, revelou-se ser interdisciplinar, demandando o aprofundamento de matérias envolvendo áreas distintas do direito, tal como o Direito de Família (separação, divórcio e dissolução da união estável e a partilha), Empresarial (tipos societários, quotas sociais e correspondente determinação e liquidação em dissolução parcial da sociedade), Civil (fraude e vícios de consentimento na partilha), Processual Civil (dissolução parcial da sociedade e incidente de desconsideração da personalidade jurídica) e Tributário (tributação na partilha e na apuração e pagamento dos haveres na dissolução parcial da sociedade).

Do ponto de vista do Direito de Família, ocupou-se no Capítulo 1 do desenvolvimento do tema dissolução da sociedade e vínculo afetivo. Em meio ao estudo e abordagem do item acerca da partilha de bens e eventuais fraudes em prejuízo ao meeiro e/ou a terceiros, observou-se que a união estável constitui instituto o qual, pelas suas características, permite, de forma mais ampla, a perpetração de fraudes, em ambas as hipóteses, quer contra o meeiro, quer contra terceiros.

Com relação ao meeiro, há uma facilidade a praticar atos fraudulentos à meação, pois prerrogativas exigidas do cônjuge para evitar dilapidação de patrimônio, tal como a outorga conjugal, no caso de imóveis ou para vendas de ascendentes a descendentes, podem facilmente ser esquivadas, uma vez que a união estável é situação de fato, podendo existir sem qualquer registro perante o Registro de Pessoas Naturais a comprová-la. Em 
sendo assim, o meeiro, em união estável, fica carente do uso de tal prerrogativa, para evitar alienação de bens.

Também é possível, por meio da união estável, prejudicar o antigo cônjuge do companheiro, declarando-se a existência de uma união estável em período superior à existente, como forma de aumentar a porção da meação devida ao(à) atual companheiro(a) em detrimento da porção de patrimônio devida ao antigo cônjuge, por força da meação.

Da mesma forma, com relação a terceiros observa-se que os danos podem ser muito maiores, se companheiros resolverem praticar atos fraudulentos.

As formas de se fraudar são inúmeras, tais como: (i) aquisição de bens em nome do companheiro, mantendo a união estável sem qualquer formalização, a fim de que os credores não encontrem bens suficientes para pagamento das dívidas; (ii) aumentar o período de convivência entre os companheiros, como forma de diminuir o patrimônio do companheiro endividado, aumentando-se a porção do patrimônio devida pela meação ao consorte, de modo a transferir bens por força de partilha, em eventual simulação de uma dissolução de união estável, a fim de prejudicar credores, eventuais demais herdeiros etc..

Com relação à forma de se remediar tais atos fraudulentos, em meio às pesquisas realizadas, não se identificou trabalhos que abordassem de forma direta e satisfatória o iter entre o reconhecimento da fraude, retorno ao status quo do bem fraudulentamente desviado e a partilha do patrimônio entre o casal. Explica-se.

Em casos comuns tal como o de ocultação de patrimônio por um dos cônjuges, há corrente doutrinária, acompanhada pela jurisprudência, segundo a qual seria suficiente mero pedido de sobrepartilha.

A situação se agrava, no entanto, quando necessário anular atos pretéritos para, a partir daí, partilhar-se o patrimônio devido ao cônjuge ou companheiro prejudicado.

$\mathrm{Na}$ jurisprudência encontrou-se ações ajuizadas contra o cônjuge fraudador e eventual terceiro que tenha participado no ato fraudulento, com pedido de indenização pela fraude perpetrada, como alternativa ao retorno do status quo ante do bem fraudulentamente desviado, que deveria compor os bens comuns para eventual sobrepartilha.

Ocorre que em casos que é necessário o retorno ao status quo ante do bem fraudulentamente desviado, em virtude da ausência de patrimônio do consorte fraudador para pagar a indenização, há um hiato sobre o procedimento a ser adotado, do ponto de vista 
da efetividade do processo. Demonstrar-se-ia nada razoável ter o consorte prejudicado que ajuizar uma demanda para pedir a anulação de um negócio jurídico para, depois de transitada em julgado, partilhar-se, por meio de pedido de sobrepartilha.

Em meio à pesquisa, também não se identificou no acervo consultado obras que abordassem de forma mais aprofundada o ajuizamento da ação rescisória, especificamente para quando apurada fraude à meação, em caso de partilha de bens litigiosa.

Com relação à partilha de quotas sociais, ela, por si só, já é matéria bastante densa, principalmente quando se envolve a sua evolução do ponto de vista societário quanto: (i) a proteção da sociedade quanto ao ingresso de qualquer outro sócio (no caso, seria o meeiro), sem consentimento ou mediante oposição dos demais, consagrando-se o princípio "socci mei socius meus socius non est" ${ }^{\prime 395}$; (ii) expressa vedação legal ao meeiro efetivar o pedido de liquidação da quota social, como forma de preservar o patrimônio da sociedade, conferindolhe tão só o direito ao recebimento da distribuição periódica dos dividendos, de forma proporcional a sua participação, e aos haveres quando da liquidação da sociedade.

Interessante é observar o embate existente entre direito à preservação do patrimônio da sociedade e direito do meeiro a receber os haveres representativos de sua participação social. Nesse sentido, a jurisprudência construiu o entendimento segundo o qual seria admitido ao ex-cônjuge ou ex-companheiro a legitimidade ao pedido de dissolução parcial da sociedade, de modo que a própria sociedade a que cujas quotas sociais foram partilhadas, efetuasse o pagamento dos haveres correspondente ao meeiro, uma vez apurado em processo judicial. Essa possibilidade, recentemente, foi prevista em lei, por meio do Código de Processo Civil de 2015, segundo já abordado no Capítulo 2.

Fato é que os Tribunais construíram entendimento segundo o qual seria bastante danoso ao meeiro a manutenção de seu vínculo com a sociedade sem qualquer previsão ou estimativa de quando receberia seus haveres, detendo direito tão somente a distribuição periódica dos lucros.

Ocorre, no entanto, que ainda está vigente o artigo 1.027 do Código Civil de 2002, que estabelece a vedação expressa quanto ao pedido de liquidação e recebimento dos haveres do meeiro, por força de dissolução de vínculo afetivo. Não houve qualquer revogação expressa desse dispositivo legal.

\footnotetext{
${ }^{395}$ Tradução livre: "o sócio do meu sócio não é meu sócio".
} 
Acredita-se que tal antinomia (= artigo 1.027 do Código Civil de 2002 x artigo 600, parágrafo único, Código de Processo Civil de 2015) pouco prejudicará o direito do meeiro a pleitear a dissolução e apuração de haveres, visto que tal já ocorria por meio de construção jurisprudencial, mediante entendimento inclusive do Superior Tribunal de Justiça, ainda que houvesse decisões na jurisprudência contrárias à legitimidade do ex-cônjuge ou excompanheiro a ajuizar a ação de dissolução parcial. Não se encontrou em meio à pesquisa nenhuma referência a implicações quanto a tal contradição no ordenamento jurídico brasileiro, sobretudo - acredita-se - em razão da recente inovação legislativa pelo Código de Processo Civil de 2015. Não foi objeto central desse trabalho uma confrontação entre os 2 (dois) dispositivos legais, ficando apenas a ressalva quanto tal aparente inconsistência no sistema ante a vigência de ambos.

No Capítulo 2, fez-se extensa explicação do procedimento por meio do qual apurase os haveres devidos por força da liquidação da quota social, quer seja por meio de dissolução parcial, a ser pago pela sociedade a qual o consorte detém participação, quer na ação de separação, divórcio ou dissolução da união estável, diretamente pelo meeiro.

Abordou-se, ainda, importante questão acerca do dissenso jurisprudencial quanto à meação da valorização da quota social, quando adquirida previamente à constância da relação afetiva. A dúvida repousa no fato de que, via de regra, os frutos dos bens particulares - no caso, a quota adquirida previamente à relação afetiva é bem particular - comunicamse, de tal modo que parte da doutrina e jurisprudência perfilha o entendimento de que a valorização da quota social deveria ser objeto de meação, no caso de que sua valorização tenha ocorrido por força de reaplicação de juros e dividendos (que seriam os frutos da participação societária).

Contrariamente, o autor filia-se ao entendimento da doutrina e jurisprudência segundo o qual o lucro apenas passa a ser fruto do cônjuge ou companheiro, a compor os bens comuns, quando deliberado entre sócios da sociedade a distribuição dos dividendos. Enquanto isso, tais lucros são da sociedade, podendo ser reinvestidos ou mantidos como reserva. Dessa forma, inexistiria meação da valorização da quota social.

No Capítulo 3, abordando-se a fraude à meação, especialmente pelo uso ilícito da pessoa jurídica, elencou-se diversas formas de se prejudicar o consorte, como tratadas pela doutrina. 
Ao referir à forma de remediar tal fraude, especialmente quando praticada com o uso de uma pessoa jurídica, tratou-se da teoria da desconsideração da personalidade jurídica, na forma inversa, por meio do qual se levanta o véu da pessoa jurídica para que seu patrimônio seja atingido por alguma obrigação atribuída ao sócio, no caso, cônjuge ou companheiro.

Ressalte-se que tal doutrina, recentemente, vem sendo aplicada também para não só levantar o véu da pessoa jurídica, mas também atingir outras pessoas naturais, quando se comprove que atuam como pessoas interpostas, popularmente alcunhadas como "laranjas", para efetivar atos fraudulentos.

Finalizando a presente conclusão, pretendeu-se, com este trabalho, realizar uma abordagem geral com relação ao instituto da partilha de quotas sociais e o uso ilícito da pessoa jurídica para fraudar a meação, de modo a contribuir, ainda que modestamente, para o estudo da matéria em exame. 


\section{REFERÊNCIAS}

ADAMEK, Marcelo Vieira von. Abuso de minoria em direito societário. São Paulo: Malheiros Ed., 2014.

AIDAR, Antonio Ivo; SILVA, Ana Gabriela López Tavares da. Prática no direito de família. São Paulo: Quartier Latin. 2009.

ALMEIDA, Amador Paes. Execução de bens dos sócios: obrigações mercantis, tributárias, trabalhistas: da desconsideração da personalidade jurídica (doutrina e jurisprudência). 10. ed. São Paulo: Saraiva, 2009.

ASCARELLI, Tullio. Problemas das sociedades anônimas e direito comparado. São Paulo: Quorum, 2008.

BARBI FILHO, Celso. Dissolução parcial de sociedades limitadas. Belo Horizonte: Mandamentos, 2004.

BEZERRA, Andréia Cristina; CASQUET, Pedro Guilherme Modenese. Apontamentos sobre a incidência de ITBI e ITCMD na partilha desigual de bens decorrentes de herança ou da extinção do regime conjugal de bens. Revista Dialética de Direito Tributário, São Paulo, n. 205, p. 19-26, out. 2012.

BÍBLIA Sagrada. Tradução da CNBB. 22.ed. São Paulo: Canção Nova, 2002.

BOOM imobiliário: bom pra quem? [Entrevista com Ermínia Maricato]. Revista do Instituto Brasileiro de Defesa do Consumidor, n. 184, fev. 2014. Disponível em: <http://www.idec.org.br/em-acao/revista/falta-fruta-na-caixinha/materia/boom-imobiliariobom-pra-quem>. Acesso em: 20 dez. 2016.

BORBA, José Edwaldo Tavares. Direito societário. 8. ed., rev., aum. e atual. Rio de Janeiro: Renovar, 2003.

BRUNO, Ferdinando. The principle "piercing the corporate veil" in Italy. International Inhouse Counsel Journal, v. 2, n. 7, 2009. Disponível em: <http://works.bepress.com/ferdinando_bruno/60/>. Acesso em: 10 jan. 2017.

CAHALI, Francisco José. Inventário, partilha, separação e divórcio consular: análise primeira de sua viabilidade à luz da Lei 11.441/2007. Revista dos Tribunais, São Paulo, v. 96, n. 865, p. 11-19, nov. 2007.

Divórcio e separação. 11. ed. rev. ampl. e atual. de acordo com o Código Civil de 2002. São Paulo: Ed. Revista dos Tribunais, 2005. 
CAHALI, Yussef Said. Fraudes contra credores: fraude contra credores, fraude à execução, ação revocatória falencial, fraude à execução fiscal e fraude à execução penal. 4. ed. rev. e atual. São Paulo: Ed. Revista dos Tribunais, 2008.

CARNEIRO, Nelson. A luta pelo divórcio. São Paulo: Ed. Lampião, 1977.

CHENG, Thomas K. The corporate veil doctrine revisited: a comparative study of the english and the U. S. Corportante Veil Doctrines. Boston College International \& Comparative Law v. 34, p. 1-83, 2011. Disponível em: <http://works.bepress.com/thomas_cheng1/6/>. Acesso em: 10 jan. 2017.

CHINELLATO, Silmara Juny de Abreu; HERKENHOFF, Henrique Geaquinto. COLTRO, Antônio Carlos Mathias; DELGADO, Mário Luiz (Coords.). Separação, divórcio, partilhas e inventários extrajudiciais. São Paulo: Método, 2007.

CHYI, Catherine R. Lessons from China: keeping divorce rates low in the modern era. Global Business \& Development Law Journal, v. 23, n. 2, p. 285-312, 2010. Disponível em: <http://digitalcommons.mcgeorge.edu/globe/vol23/iss2/5>. Acesso em: 29 out. 2016.

COELHO, Clarisse; GAROUPA, Nuno. Do divorce law reforms matter for divorce rates evidence from Portugal. Empirical Legal Stud, v. 3, p. 525-527, 2006. Disponível em: <http://scholarship.law.tamu.edu/ facscholar/445>. Acesso em: 29 out. 2016.

COMPARATO, Fábio Konder; CALIXTO FILHO, Salomão. O poder de controle na sociedade anônima. 6. ed. rev. e atual. Rio de Janeiro: Forense, 2014.

CRIBARI, Giovani. Ação, processo e procedimento em relação à separação e ao divórcio, da partilha e do registro. Revista de Processo, São Paulo, v. 4, n. 16, p. 177-198, out./dez. 1979.

DAVIES, Paul. Introduction to company law. 2. ed. London: Oxford University Press, 2010.

DELGADO, Mario Luiz. Divórcio. In: PEREIRA, Rodrigo da Cunha (Org.). Tratado de direito de família. Belo Horizonte: IBDFAM, 2015. p. 627-680.

DIAS, Maria Berenice. Manual de direito das famílias. 8. ed. rev. e atual. São Paulo: Ed. Revista dos Tribunais, 2011.

DICIONÁRIO Brasileiro da Língua Portuguesa. São Paulo: Melhoramentos, 2015. Disponível em <http://michaelis.uol.com.br/busca?id=b982v>. Acesso em: 03 jan. 2017.

DOMINGUES, Paulo de Tarso. Variações sobre o capital social. Coimbra: Almedina, 2013.

DONINI, Antonio Carlos. Meu bem, meus bens. São Paulo: Ed. Klarear, 2009.

ESTRELLA, Hernani. Apuração dos haveres do sócio. 2. ed. Rio de Janeiro: Forense, 1992. 
FARIAS, Cristiano Chaves de; ROSENVALD, Nelson. Curso de direito civil: famílias. 7. ed. rev. ampl. e atual. São Paulo: Atlas, 2015. v. 6.

FAZZIO JÚNIOR, Waldo. Manual de direito comercial. 15. ed. -. São Paulo: Atlas, 2014.

FONSECA, Priscila M. P. Corrêa da. Dissolução parcial, retirada e exclusão de sócio. 5. ed. São Paulo: Atlas, 2012.

FRANÇA, Erasmo Valladão Azevedo e Novaes. "Affectio societatis": um conceito jurídico superado no moderno direito societário pelo conceito de "fim social". In: ADAMEK, Marcelo Vieira von (Coord.). Temas de direito societário, falimentar e teoria da empresa. São Paulo: Malheiros Ed., 2009.

FRANCE. Code Civil des français du 21 mars 1804 (30 Ventôse de l'An XII). (Mémorial A $\mathrm{n}^{\circ} \quad 5 \quad$ de 1804). Disponível em: <http://www.legilux.public.lu/leg/a/archives/1804/0005/a005.pdf>. Acesso em: 12 nov. 2016.

FUNDAÇÃO INSTITUTO DE PESQUISAS CONTÁBEIS, ATUARIAIS E FINANCEIRAS - FIPECAFI. Avaliação de empresas: da mensuração contábil à econômica. Organizado por Eliseu Martins. 1. ed. 8. reimpr. São Paulo: Atlas, 2012.

GOLDEN, Paul. Three in 10 americans admit to financial deception with partners. National Endowment for Financial Education (NEFE) (Jan. 14, 2011). Disponível em: $<$ http://www.nefe.org/press-room/news/admitting-to-financial-deceptions.aspx >. Acesso em: 04 jan. 2017.

GOUGH, Aidan R. Community property and family law: The Family Law Act of 1969. Cal Law Trends and Developments, n. 1, p. 271-305, Jan. 1970. Disponível em: <http://digitalcommons.law.ggu.edu/cgi/viewcontent.cgi?article=1057\&context=callaw >. Acesso em: 29 out. 2016.

HARADA, Kiyoshi. Desigualdade na partilha. Disponível em: <http://www.haradaadvogados.com.br. Acesso em: 02 nov. 2016.

HIGUCHI, Hiromi. Imposto de Renda das empresas: interpretação e prática: atualizado até 10-01-2012. 37. ed. São Paulo: IR Publicações, 2012.

HOU, Caline. A bit-ter divorce: using bitcoin to hide marital assets. North Carolina Journal of Law \& Technology, v. 16, n. 1, p. 74-105, 2014. Disponível em: <http://scholarship.law.unc.edu/ncjolt/vol16/iss5/3> Acesso em: 07 jan. 2017.

INSTITUTO BRASILEIRO DE GEOGRAFIA E ESTATÍSTICA. IBGE. Estatísticas do Registro Civil 2014. Rio de Janeiro: IBGE, 2014. v. 41.

LIMA, Alvino. A fraude no direito civil. São Paulo: Saraiva, 1965. 
LONGO, José Henrique. Aspectos tributários das estruturas empresariais. In: PRADO, Roberta Nioac; PEIXOTO, Daniel Monteiro; SANTI, Eurico Marcos Diniz de (Coords.). Direito societário: estratégias societárias, planejamento tributário e sucessório. São Paulo: Saraiva, 2009.

; PHEBO, Márcia Setti; KIGNEL; Luiz. Planejamento sucessório. São Paulo: Noeses, 2014.

LUCENA, José Waldecy. Das sociedades limitadas. 5. ed., ampl. em face do novo Código civil, com formulário. Rio de Janeiro: Renovar, 2003.

MACEY, Jonathan R.; ENRIQUES, Luca. Creditors versus capital formation: the case against the European legal capital rules". Faculty Scholarship Series. Paper, 1413, 2001. Disponível em <http://digitalcommons.law.yale.edu/fss_papers/1413>. Acesso em: $13 \mathrm{dez}$. 2016.

; MITTS, Joshua. Finding order in the Morass: the three real justifications for piercing the corporate veil. Cornell Law Review, v. 100, n. 1, p. 99-156, 2014. Disponível em: <http://scholarship.law.cornell.edu/clr/vol100/iss1/2>. Acesso em: 10 jan. 2017.

MADALENO, Rolf. Curso de direito de família. Rio de Janeiro: Forense, 2009.

A desconsideração judicial da pessoa jurídica e da interposta pessoa física no direito de família e no direito das sucessões. Rio de Janeiro: Forense, 2009.

Antônio Carlos Mathias; DELGADO, Mário Luiz (Coords.). Separação, divórcio, partilhas e inventários extrajudiciais. São Paulo: Método, 2007.

MALHEIROS, Antonio Carlos. Teoria da desconsideração inversa da personalidade jurídica aplicada aplicada às relações familiares. In: ADAMEK, Marcelo Vieira von (Coord.). Temas de direito societário e empresarial contemporâneos. São Paulo: Malheiros Ed., 2011.

MALHEIROS FILHO, Fernando. O procedimento de partilha na separação judicial, no divórcio e na união estável. Disponível em: <http://www.gontijofamilia.adv.br/2008/artigos_pdf/Fernando_Malheiros_Filho/procedimento.pdf>. Acesso em: 22 dez. 2016.

MALUF, Carlos Alberto Dabus; MALUF, Adriana Caldas do Rego Freitas Dabus. Curso de direito de família. São Paulo: Saraiva, 2013.

MARSHALL, Laura A. What god has united man will now divide: divorce referendum changes law of 60 years. Ga. J. Int'l \& Comp. L., v. 26, p. 505-520, 1997. Disponível em: <http://digitalcommons.law.uga.edu/gjicl/vol26/iss2/9>. Acesso em: 29 out. 2016.

MARTINS, Eliseu; GELBCKE, Ernesto Rubens; SANTOS, Ariovaldo dos; IUDÍCIBUS, Sérgio de. Manual de contabilidade societária: aplicável a todas as sociedades de acordo com as normas internacionais e do CPC. 2. ed. São Paulo: Atlas, 2013. 
MIRANDA, Francisco Cavalcanti Pontes de. Dissolução da sociedade conjugal e eficácia jurídica do casamento. Atualizado por Rosa Maria Barreto Borriello de Andrade Nery. 1. ed. São Paulo: Ed. Revista dos Tribunais, 2012. (Coleção tratado de direito privado: parte especial).

Tratado de direito privado: parte especial. Rio de Janeiro: Borsoi, 1972. t. 49.

NASCIMBENI, Asdrubal Franco. A aplicação da teoria da desconsideração da personalidade jurídica às sociedades anônimas. Revista de Direito Bancário e do Mercado de Capitais, São Paulo, ano 16, n. 61, jul./set. 2013.

O'BRIEN, Raymond C. Family-law's challenge to religious liberty. appalachian school of law. Expresso, Apr. 2012. Disponível em: 〈http://works.bepress.com/raymond_obrien/7>. Acesso em: 29 out. 2016.

OLIVEIRA, Celso Marcelo de. Tratado de direito empresarial brasileiro: teoria geral do direito societário. Campinas: LZN, 2004.

OLIVEIRA, Euclides Benedito de. Efeitos materiais da separação judicial e do divórcio: aspectos controvertidos da partilha de bens. Revista do Instituto dos Advogados de São Paulo, São Paulo, v. 3, n. 5, p. 142-160, jan./jun. 2000.

OLIVEIRA, Ricardo Mariz de. Fundamentos do imposto de renda. São Paulo: Quartier Latin, 2008.

ORNELAS, Martinho Maurício Gomes de. Avaliação de sociedades. Apuração de haveres em processos judiciais. 2. ed. São Paulo: Atlas, 2003.

PARENTONI, Leonardo Netto. Desconsideração da personalidade jurídica: aplicação às empresas familiares. In: COELHO, Fábio Ulhoa; FÉRES, Marcelo Andrade (Coords.). Empresa familiar: estudos jurídicos. São Paulo: Saraiva, 2014.

PEDREIRA, José Luiz Bulhões. Direito das companhias. Coordenadores Alfredo Lamy Filho e José Luiz Pedreira. 1. ed. Rio de Janeiro: Forense, 2009.

PEREIRA, Áurea Pimentel. Divórcio e separação no novo Código Civil. Rio de Janeiro: Renovar, 2004.

PEREIRA, Rodrigo da Cunha. União estável. In: PEREIRA, Rodrigo da Cunha (Org.). Tratado de direito de família. Belo Horizonte: IBDFAM, 2015.

PEREIRA, Sérgio Gischkow. Calma com a separação e o divórcio! Disponível em: <http://www.mauricio.bastos.nom.br/noticias/6333-calma-separacao-divorcio.html>. 
REPORT of the high level group of company law experts on a modern regulatory framework for company law in Europe. Brussels, 4 November 2002. Disponível em: <http://ec.europa.eu/internal_market/company/docs/modern/report_en.pdf >. Acesso em: 13 dez. 2016.

REQUIÃO, Rubens. Aspectos modernos de direito comercial: estudos e pareceres. São Paulo: Saraiva, 1977.

RODRIGUES, Daniel Gustavo de Oliveira Colnago. Abuso da personalidade jurídica e fraude no direito de família: alguns aspectos materiais e processuais. Revista Dialética de Direito Processual, São Paulo, n. 99, p. 9-22, jun. 2011.

SIMÃO, José Fernando. A Emenda Constitucional n 66: a revolução do século em matéria de Direito de família: a passagem de um sistema antidivorcista para o divorcista pleno. Revista do Advogado, São Paulo, v. 31, n. 112, p. 64-78, jul. 2011.

SIMIONATO, Frederico A. Monte. Tratado de direito societário. Rio de Janeiro: Forense, 2009. v. 1.

SOUZA, Gelson Amaro de. Desconsideração da personalidade jurídica no CPC-2015. Revista de Processo, São Paulo, v. 41, n. 255, p. 91-113, maio 2016.

TARTUCE, Flávio. Direito civil: direito de família. 10. ed. rev., atual. e ampl. Rio de Janeiro: Forense; São Paulo: Método, 2015. v. 5.

TEIXEIRA, Egberto Lacerda. Das sociedades por quotas de responsabilidade limitada. 2. ed. São Paulo: Quartier Latin, 2006.

THEODORO JÚNIOR, Humberto. Fraude contra credores: a natureza da sentença pauliana. 2. ed. rev. atual. e ampl. Belo Horizonte: Del Rey. 2001.

TILBERY, Henry. A tributação dos ganhos de capital. In: NOGUEIRA, Ruy Barbosa et al. (Coords.). Direito tributário. São Paulo: Jose Bushatsky Editor, 1971.

UNIFORM Marriage and Divorce Act (UMDA). Disponível em: <http://www.uniformlaws.org/shared/docs/Marriage\%20and\%20Divorce\%20Act/UMDA \%201973.pdf>. Acesso em: 29 out. 2016.

VENOSA, Silvio; RODRIGUES, Cláudia. Direito civil: direito empresarial. 6. ed. rev., atual. e ampl. São Paulo: Atlas, 2016.

VERÇOSA, Haroldo Malheiros Duclerc. Curso de direito comercial: teoria geral das sociedades: as sociedades em espécie do Código Civil. 2. ed. rev. e atual. São Paulo: Malheiros Ed., 2010. v. 2. 
WALD, Arnoldo. Sociedade de pessoas organizada sob a forma de sociedade limitada. Direito dos sócios de bloquear o ingresso do terceiro adquirente das quotas, por ausência de affectio societatis e conflito de interesses do terceiro com a sociedade. Revista de Direito Bancário e do Mercado de Capitais, São Paulo, v. 36, abr. 2007.

\section{LEGISLAÇÃO E JURISPRUDÊNCIA}

BRASIL, Lei $n^{o}$ 9.532, de 10 de dezembro de 1997. Disponível em: <https://www.planalto.gov.br/ccivil_03/leis/L9532.htm>. Acesso em: 03 jan. 2017.

Código Tributário Nacional. Lei ${ }^{\circ}$ 5.172, de 25 de outubro de 1966. Disponível em: <https://www.planalto.gov.br/ccivil_03/leis/L5172.htm〉. Acesso em: 22 dez. 2016.

. Constituição Federal de 1967, de acordo com a Emenda Constitucional $n^{o}$ 9, de
1969. <http://www.planalto.gov.br/ccivil_03/Constituicao/Constituicao67EMC69.htm>. Acesso em: 20 out. 2016.

. Decreto $\mathrm{n}^{\mathrm{o}} 3.707$, de 10 de janeiro de 1919. Corrige enganos com que foi publicada a lei n. 3.644, de 31 de dezembro de 1918. Disponível em <http://www.planalto.gov.br/CCIVIL_03/decreto/Historicos/DPL/DPL3708.htm>. Acesso em: 06 dez. 2016.

Decreto-Lei ${ }^{\circ}$ 1.608, de 18 de setembro de 1939. Código de Processo Civil. Disponível em: <https://www.planalto.gov.br/ccivil_03/decreto-lei/19371946/Del1608.htm> Acesso em: 24 dez. 2016.

Decreto-Lei $n^{o}$ 5.452, de $1^{o}$ de maio de 1943. Disponível em: <http://www.planalto.gov.br/ccivil_03/decreto-lei/Del5452.htm>. Acesso em: 10 jan. 2017.

- Emenda Constitucional $n^{o}$ 66, de 13 de julho de 2010. Disponível em: <http://www.planalto.gov.br/ccivil_03/Constituicao/Emendas/Emc/emc66.htm>. Acesso em: 20 dez. 2016.

_Lei n. 8.218, de 29 de agosto de 1991. Disponível em: <https://www.planalto.gov.br/ccivil_03/LEIS/L8218.htm>. Acesso em: 31 dez. 2016.

. Lei $\mathrm{n}^{\circ}$ 10.406, de 10 de janeiro de 2002. Código Civil. Disponível em: <http://www.planalto.gov.br/ccivil_03/leis/2002/L10406.htm>. Acesso em: 13 nov. 2016. Acesso em: 13 nov. 2016; 06, 08 jan. 2017.

. Lei n ${ }^{\circ} 13.105$, de 16 de março de 2015. Código de Processo Civil. Disponível em: <https://www.planalto.gov.br/ccivil_03/_ato2015-2018/2015/lei/113105.htm> Acesso em: 27 dez. 2016, 10 jan. 2017. 
BRASIL. Lei $n^{o}$ 13.259, de 16 de março de 2016. Disponível em: <http://www.planalto.gov.br/ccivil_03/_Ato2015-2018/2016/Lei/L13259.htm>. Acesso em: 12 jan. 2017.

. Lei $\mathrm{n}^{\circ}$ 3.071, de $1^{\circ}$ de janeiro de 1916. Código Civil. Disponível em: <https://www.planalto.gov.br/ccivil_03/leis/L3071.htm>. Acesso em: 20 nov. 2016.

Lei $\mathrm{n}^{\circ}$ 5.869, de 11 de janeiro de 1973. Institui o Código de Processo Civil. Disponível em: <http://www.planalto.gov.br/ccivil_03/leis/L5869.htm>. Acesso em: 24 dez. 2016.

Lei $\mathrm{n}^{\circ} 6.015$, de 31 de dezembro de 1973. Dispõe sobre os registros públicos, e dá outras providências. Disponível em: <http://www.planalto.gov.br/ccivil_03/leis/L6015original.htm>. Acesso em: 13 nov. 2016.

Lei no 6.404, de 15 de dezembro de 1976. Dispõe sobre as Sociedades por Ações. Disponível em: <https://www.planalto.gov.br/ccivil_03/leis/L6404consol.htm>. Acesso em: 07 dez. 2016; 10 jan. 2017.

- Lei $n^{o}$ 7.841, de 19 de outubro de 1989. Disponível em: <https://www.planalto.gov.br/ccivil_03/leis/L7841.htm>. Acesso em: 20 dez. 2016.

Lei $n^{o}$ 8.078, de 11 de setembro de 1990. Disponível em <http://www.planalto.gov.br/ccivil_03/leis/L8078.htm>. Acesso em: 03 jan. 2017.

Lei $\mathrm{n}^{\circ}$ 8.971, de 29 de dezembro de 1994. Regula o direito dos companheiros a $\begin{array}{llll}\text { alimentos } & e & \grave{a} & \text { sucessão. }\end{array}$ em:<http://www.planalto.gov.br/ccivil_03/leis/L8971.htm>. Acesso em: 19 nov. 2016.

Lei $n^{o}$ 8.981, de 20 de janeiro de 1995. Disponível em: <http://www.planalto.gov.br/ccivil_03/LEIS/L8981.htm>. Acesso em: 12 jan. 2017.

Lei $\mathrm{n}^{\circ}$ 9.278, de 10 de maio de 1996. Regula o $\S 3^{\circ}$ do art. 226 da Constituição Federal. Disponível em: <http://www.planalto.gov.br/ccivil_03/leis/L9278.htm>. Acesso em: 19 nov. 2016.

—. Receita Federal do Brasil. Instrução Normativa SRF $n^{o} 11$, de 21 de fevereiro de 1996. Disponível em: <http://normas.receita.fazenda.gov.br/sijut2consulta/link.action?visao=anotado\&idAto=13 034>. Acesso em: 12 jan. 2017.

Receita Federal do Brasil. Instrução Normativa SRF no 84, de 11 de outubro de 2002. Disponível em: <http://normas.receita.fazenda.gov.br/sijut2consulta/link.action?idAto $=14400 \&$ visao $=$ anot ado>. Acesso em: 21 jan. 2017. 
BRASIL. Receita Federal do Brasil. Solução de Consulta COSIT n ${ }^{o} 131$, de 31 de agosto de 2016. Disponível

em: $<$ http://normas.receita.fazenda.gov.br/sijut2consulta/link.action?idAto $=77263 \&$ visao $=$ com pilado>. Acesso em: 12 jan. 2017.

Recurso especial no 1.173.931-RS, Relator Ministro Paulo de Tarso Sanseverino da $3^{\text {a }}$ Turma do Superior Tribunal de Justiça, julgado no dia 22/10/2013. Disponível em: <http://www.stj.jus.br/SCON/jurisprudencia/toc.jsp?processo=1173931\&\&tipo_visualizac $\mathrm{ao}=\mathrm{RESUMO} \& \mathrm{~b}=\mathrm{ACOR} \&$ thesaurus=JURIDICO\&p=true $>$. Acesso em: 03 jan. 2017.

. Superior Tribunal de Justiça, Recurso especial 105.667/SC, Rel. Ministro BARROS MONTEIRO, QUARTA TURMA, julgado em 26/09/2000. Disponível em: $<$ https://ww2.stj.jus.br/processo/revista/inteiroteor/?num_registro=199600542767\&dt_publ icacao=06/11/2000>. Acesso em: 23 dez. 2016.

Superior Tribunal de Justiça, Recurso especial 114.708/MG, Rel. Ministro WALDEMAR ZVEITER, Rel. p/ Acórdão Ministro CARLOS ALBERTO MENEZES DIREITO, TERCEIRA TURMA, julgado em 19/02/2001. Disponível em <http://www.stj.jus.br/SCON/jurisprudencia/toc.jsp?processo=114708\&\&tipo_visualizaca $\mathrm{o}=\mathrm{RESUMO} \& \mathrm{~b}=\mathrm{ACOR} \&$ thesaurus=JURIDICO\&p=true $>$. Acesso em: $23 \mathrm{dez} .2015$.

Superior Tribunal de Justiça, Recurso Especial 1305767/MG, Rel. Ministro RICARDO VILLAS BÔAS CUEVA, TERCEIRA TURMA, julgado em 03/11/2015. Disponível em: <https://ww2.stj.jus.br/processo/revista/inteiroteor/?num_registro=201200192793\&dt_publ icacao=16/11/2015>. Acesso em: $22 \mathrm{dez} .2016$.

Superior Tribunal de Justiça, Recurso Especial 328.297/RJ, Rel. Ministro RUY ROSADO DE AGUIAR, QUARTA TURMA, julgado em 16/10/2001. Disponível em: $<$ https://ww2.stj.jus.br/processo/revista/inteiroteor/?num_registro=200100788837\&dt_publ icacao=18/02/2002>. Acesso em: 22 dez. 2016.

. Superior Tribunal de Justiça, Recurso Especial 605.600/SP, Rel. Ministra NANCY ANDRIGHI, TERCEIRA TURMA, julgado em 24/08/2004. Disponível em: $<$ https://ww2.stj.jus.br/processo/revista/inteiroteor/?num_registro=200301968179\&dt_publ icacao=13/12/2004>. Acesso em: 07 jan. 2017.

Superior Tribunal de Justiça. Recurso especial 1236916/RS, Rel. Ministra NANCY ANDRIGHI, TERCEIRA TURMA, julgado em 22/10/2013. Disponível em: <https://ww2.stj.jus.br/processo/revista/inteiroteor/?num_registro=201100311609\&dt_publ icacao=28/10/2013>. Acesso em 11/01/2017.

Superior Tribunal de Justiça. Recurso especial 1537107/PR, Rel. Ministra NANCY ANDRIGHI, TERCEIRA TURMA, julgado em 17/11/2016. Disponível em: <http://www.stj.jus.br/SCON/jurisprudencia/doc.jsp?ementa=mancomunh\%E3o\&b=ACO $\mathrm{R} \& \mathrm{p}=$ true \&t=JURIDICO\&l=10\&i=1>. Acesso em: $28 \mathrm{dez} .2016$. 
BRASIL. Superior Tribunal de Justiça. Recurso Especial 72.997/SP, Rel. Ministro HUMBERTO GOMES DE BARROS, TERCEIRA TURMA, julgado em 18/05/2004. Disponível em: <https://ww2.stj.jus.br/processo/revista/inteiroteor/?num_registro=199500432200\&dt_publ icacao=16/08/2004>. Acesso em: 22 dez. 2016.

Superior Tribunal de Justiça. Recurso Especial 1236916/RS, Rel. Ministra NANCY ANDRIGHI, TERCEIRA TURMA, julgado em 22/10/2013. Disponível em: $<$ https://ww2.stj.jus.br/processo/revista/inteiroteor/?num_registro=201100311609\&dt_publ icacao=28/10/2013> . Acesso em: 10 jan. 2017.

Superior Tribunal de Justiça. Recurso Especial $n^{\circ}$ 1335619/SP, da TERCEIRA TURMA, Brasília, DF, 03/03/2015. Disponível em: <https://ww2.stj.jus.br/processo/revista/documento/mediado/?componente=ITA\&sequenci al $=1307862 \&$ num_registro $=201202697785 \&$ data $=20140603 \&$ formato $=P D F>$. Acesso em: 21 dez. 2016.

. Superior Tribunal de Justiça. Recurso Especial no 1335619/SP, Rel. Ministra Nancy Andrighi da $3^{\text {a }}$ Turma, Brasília, DF, 03/03/2015. Disponível em: <https://ww2.stj.jus.br/processo/revista/documento/mediado/?componente=ITA\&sequenci al $=1307862 \&$ num_registro $=201202697785 \&$ data $=20140603 \&$ formato $=P D F>$. Acesso em: 21 dez. 2016.

Supremo Tribunal Federal. Súmula $n^{o}$ 265. Disponível em: <http://www.stf.jus.br/portal/jurisprudencia/menuSumarioSumulas.asp?sumula=3021 $>$. Acesso em: 28 dez. 2016.

. Tribunal de Justiça do Estado de São Paulo, Agravo de Instrumento no 9017334 65.1998.8.26.0000, Relator(a): Júlio Vidal; Órgão julgador: $7^{\mathrm{a}}$ Câmara de Direito Privado; Data de registro: 29/04/1998. Disponível em: $<$ https://esaj.tjsp.jus.br/cjsg/getArquivo.do?cdAcordao=1361455\&cdForo=0\&vlCaptcha= DVMyD>. Acesso em: 24 dez. 2016.

. Tribunal de Justiça do Estado de São Paulo, Agravo de Instrumento n ${ }^{\circ} 2085463$ 85.2014.8.26.0000, Relator(a): Fernandes Lobo, 22 ${ }^{\mathrm{a}}$ Câmara de Direito Privado; Data do julgamento: 26/06/2014 Disponível em: <https://esaj.tjsp.jus.br/cjsg/getArquivo.do?cdAcordao=7666033\&cdForo=0>. Acesso em: 22 dez. 2016.

- Tribunal de Justiça do Estado de São Paulo, Apelação n ${ }^{\circ}$ 000282002.2009.8.26.0220, Relator: Cesar Ciampolini, $10^{\text {a }}$ Câmara de Direito Privado, julgamento em 15/12/2015. Disponível em: $<$ https://esaj.tjsp.jus.br/cjsg/getArquivo.do?cdAcordao=9086812\&cdForo=0\&vlCaptcha $=$ QaQfc>. Acesso em: 22 dez. 2016. 
BRASIL. Tribunal de Justiça do Estado de São Paulo, Apelação no 019185402.2008.8.26.0100 Relator(a): Vito Guglielmi; Órgão julgador: 6 ${ }^{\mathrm{a}}$ Câmara de Direito Privado; Data do julgamento: 17/02/2011. Disponível em <https://esaj.tjsp.jus.br/cjsg/getArquivo.do?cdAcordao=4969021\&cdForo=0>. Acesso em: 22 dez. 2016.

- Tribunal de Justiça do Estado de São Paulo, Apelação no ${ }^{\circ}$ 911970597.2004.8.26.0000 Relator(a): Maurício Ferreira Leite; Órgão julgador: $21^{\mathrm{a}}$ Câmara de Direito Privado; Data do julgamento: 16/09/2009. Disponível em: $<$ https://esaj.tjsp.jus.br/cjsg/getArquivo.do?cdAcordao=4078827\&cdForo=0>. Acesso em: 22 dez. 2016.

- Tribunal de Justiça do Estado de São Paulo, Apelação no 917412802.2007.8.26.0000 Relator(a): Elcio Trujillo; Comarca: Assis; Órgão julgador: $7^{\text {a }}$ Câmara de Direito Privado; Data do julgamento: 07/04/2010. Disponível em: $<$ https://esaj.tjsp.jus.br/cjsg/getArquivo.do?cdAcordao=4421528\&cdForo=0>. Acesso em: 22 dez. 2016.

- Tribunal de Justiça do Estado de São Paulo. Ação Rescisória no 210451074.2016.8.26.0000 Relator(a): Alexandre Lazzarini; Órgão julgador: $9^{a}$ Câmara de Direito Privado; Data do julgamento: 21/06/2016. Disponível em: $<$ https://esaj.tjsp.jus.br/cjsg/getArquivo.do?cdAcordao=9535521\&cdForo=0>. Acesso em: 22 dez. 2016.

- Tribunal de Justiça do Estado de São Paulo. Ação Rescisória no 9050775 22.2007.8.26.0000 Relator(a): Egidio Giacoia; Órgão julgador: $3^{\mathrm{a}}$ Câmara de Direito Privado; Data do julgamento: 27/05/2008. Disponível em: $<$ https://esaj.tjsp.jus.br/cjsg/getArquivo.do?cdAcordao=2630927\&cdForo=0\&vlCaptcha=i Ezet>. Acesso em: 22 dez. 2016.

. Tribunal de Justiça do Estado de São Paulo. Agravo de Instrumento no 214210107.2015.8.26.0000. Relator(a): Antonio Nascimento; Comarca: São Paulo; Órgão julgador: 26 ${ }^{\text {a }}$ Câmara de Direito Privado; Data do julgamento: 27/08/2015. Disponível em $<$ https://esaj.tjsp.jus.br/cjsg/getArquivo.do?cdAcordao=8753845\&cdForo=0>. Acesso em: 10 jan. 2017.

. Tribunal de Justiça do Estado de São Paulo. Agravo de Instrumento no 219699933.2016.8.26.0000. Relator(a): Rebello Pinho; Comarca: São Paulo; Órgão julgador: $20^{\mathbf{a}}$ Câmara de Direito Privado; Data do julgamento: 05/12/2016. Disponível em: $<$ https://esaj.tjsp.jus.br/cjsg/getArquivo.do?cdAcordao=10046223\&cdForo=0\&vlCaptcha= wQxrb>. Acesso em: 10 jan. 2017.

. Tribunal de Justiça do Estado de São Paulo. Agravo de Instrumento no11981030/0. Rel. Des. Pereira Calças. 29a Câmara da Seção de Direito Privado. J. 26/11/2008. Disponível em: $<$ https://esaj.tjsp.jus.br/cjsg/getArquivo.do?cdAcordao=3373942\&cdForo=0\&vlCaptcha= YPfsw>. Acesso em: 10 jan. 2017. 
BRASIL. Tribunal de Justiça do Estado de São Paulo. Apelação n ${ }^{\circ}$ 012370208.2008.8.26.0000 Relator(a): Erickson Gavazza Marques; Órgão julgador: $5^{\text {a }}$ Câmara de Direito Privado; Data do julgamento: 31/07/2013. Disponível em $<$ https://esaj.tjsp.jus.br/cjsg/getArquivo.do?cdAcordao=6893789\&cdForo=0\&vlCaptcha $=$ BQYYR>. Acesso em: 24 dez. 2016.

Tribunal de Justiça do Estado de São Paulo. Apelação no 003238417.2011.8.26.0071, Relator(a): Marcondes D'Angelo da 25 Câmara de Direito Privado, data do julgamento: 27/06/2013. Disponível em: $<$ https://esaj.tjsp.jus.br/cjsg/getArquivo.do?cdAcordao=6840789\&cdForo=0>. Acesso em: 22 dez. 2016.

- Tribunal de Justiça do Estado de São Paulo. Apelação no 001143047.2012.8.26.0577; Relator(a): Fábio Podestá. Órgão julgador: $5^{\mathrm{a}}$ Câmara de Direito Privado. Data do julgamento: 26/02/2014. Disponível em: $<$ https://esaj.tjsp.jus.br/cjsg/getArquivo.do?cdAcordao=7394560\&cdForo=0>. Acesso em: 22 dez. 2016.

. Tribunal de Justiça do Estado de São Paulo. Apelação n ${ }^{\circ}$ 005634793.2013.8.26.0100 Relator(a): Rômolo Russo; Órgão julgador: $7^{\mathrm{a}}$ Câmara de Direito Privado; Data do julgamento: 18/05/2016. Disponível em: $<$ https://esaj.tjsp.jus.br/cjsg/getArquivo.do?cdAcordao=9478720\&cdForo=0>. Acesso em: 22 dez. 2016.

- Tribunal de Justiça do Estado de São Paulo. Apelação n ${ }^{\circ}$ 906713333.2005.8.26.0000. Relator(a): Enio Zuliani; Comarca: Comarca nâo informada; Órgão julgador: $4^{a}$ Câmara de Direito Privado; Data de registro: 22/06/2007. Disponível em: $<$ https://esaj.tjsp.jus.br/cjsg/getArquivo.do?cdAcordao=1020561\&cdForo=0\&vlCaptcha $=\mathrm{u}$ ejby>. Acesso em: 10 jan. 2017.

Tribunal de Justiça do Estado de São Paulo. Dúvida. Processo 104893526.2015.8.26.0100. Juíza Tania Mara Ahua. $5^{\circ}$ Oficial de Registro de Imóveis de São Paulo. Disponível

em: <https://esaj.tjsp.jus.br/pastadigital/abrirDocumentoEdt.do?cdProcesso=2S000GUJ00000 $\& \mathrm{cdForo}=100 \& \mathrm{cdDoc}=44162550 \& \mathrm{cdServico}=800000 \&$ tpOrigem $=2 \&$ flOrigem $=\mathrm{P} \&$ nmAli as=PG5JM\&ticket=s95oU\%2F6j2impvuoV56F\%2BRMo7DbaRQP0ciU9v3jTQY9CCy4I UZbNOKN4F0x YudKlvhBBAMCwaJBFPuH\%2BEVr17XZElur\%2Bk8m8uHYKEq9vnB jyqSA7flGRkiQ6YRolbKx32R4eK\%2Fy2raNIpBC2z19V6GmIx0lxUy6PjOTujfOYlFMw \%2FsSDSzOeiQYVkS72c9OwT80b\%2BGPXuLcL0kYS2o37seA\%3D\%3D>. Acesso em: 10 jan. 2017.

Tribunal de Justiça do Estado do Rio Grande do Sul, Apelação no $70005530803,8^{\text {a }}$ Câmara Cível, Relator(a) Des. Alfredo Guilherme Englert, julgado em 14.08.2003. Disponível em <http://www1.tjrs.jus.br/site_php/consulta/download/exibe_documento.php?numero_proce sso=70005530803\&ano=2003\&codigo=202081 >. Acesso em: 22 dez. 2016. 
COMUNIDADES ECONÔMICAS EUROPEIAS. Primeira Directiva 68/151/CEE do Conselho, de 9 de Março de 1968. Disponível em: <http://eur-lex.europa.eu/legalcontent/EN-PT-FR/TXT/?uri=CELEX:31968L0151\&from=PT>. Acesso em: 13 dez. 2016.

COMUNIDADES EUROPEIAS. Diretiva 2012/30/UE do Parlamento Europeu e do Conselho, de 25 de outubro de 2012. Disponível em: <http://eur-lex.europa.eu/legalcontent/EN-PT-FR/TXT/?uri=URISERV:126004\&from=ES>. Acesso em: 13 dez. 2016. 